\title{
Gesture's community: Social organization in multimodal conduct
}

\author{
G R E G O R Y M A T O E S I A N \\ Department of Criminology, Law and Justice \\ University of Illinois at Chicago \\ matoesia@uic.edu
}

\section{A B S T R A C T}

This article analyzes the multimodal integration of gesture, talk, and sociocultural context. More specifically, I investigate how forms of Gemeinschaft/ Gesellshaft community are embodied in the concrete details of multimodal form - in the iconic interplay of multimodal practice and symbolic forms of social organization. Using a focus group interview of community policing training, I show how criss-crossing laminations of participation emerge through novel gestural configurations like multimodal quotation and pragmatic beats to not only pace the rhythm of speech but simultaneously plot the spatial coordinates of social organization. In the course of events, we see how speakers integrate gesture, gaze, and postural orientation into the stream of their utterances to project rhythmically infused meanings of communal identity, social solidarity, and cultural opposition. (Multimodality, community, legal discourse)*

\section{N T R O D U C T I O N}

This article examines the complex integration of gesture, talk, and sociocultural context. More specifically, I examine how community as a symbolic form of social organization is embodied in and reproduced through the situated details of multimodal conduct. ${ }^{1}$ While considerable research has examined the role of cospeech or idiosyncratic gestures in utterance construction and the mutual coordination of speech and gesture in the constitution of meaning (McNeill 1992, 2005; Goodwin 2000; Kendon 2004; Streeck 2009), little research has explored how multimodal conduct indexes symbolic forms of social organization. By the same token, while recent micro studies have analyzed the discursive constitution of cultural identities and oppositions and thus moved beyond classic notions of community as a geographically bounded space (Potter \& Reicher 1987; Widdicombe 1998; Wodak, Cillia, Reisigl, \& Liebhart 1999; Hester \& Housley 2002), little research has considered how a symbolic sense of community emerges in and through multimodal form, in the improvisational performance of speech-gesture synchronization. This study analyzes how speakers mobilize multimodal resources to not only reference community but enact it in the reflexive interplay of gesture, gaze, and talk. 
Community constitutes one of the classic - yet "highly contested" and ambiguous (Neal \& Waters 2008:280) — concepts in social science, playing a major explanatory role in sociology in general and criminology in particular (Cohen 1985; Bauman 2001). ${ }^{2}$ Ferdinand Tonnies's Gemeinschaft/Gesellshaft inaugurated the quest for a host of now familiar oppositions in the study of social organization: locality, familiarity, sameness, tradition, and rural on the one hand and detachment, difference, bureaucratic rationality, and urban on the other. A glimpse into the writings of Karl Marx, Emile Durkheim, and Max Weber reveals a preoccupation with the massive upheaval and transformation in social life from a world of regular social interaction among intimates to the artificial means-ends impersonality of modern capitalism. Despite inherent problems of reification and imprecision, the concept still thrives as a pregiven explanatory device based on ideal type imagery of geographic location or small-scale population aggregate in which community structure shapes individual conduct (e.g. how community disorganization influences crime rates). Criminology, in particular, thrives along such lines with significant policy implications, as in the case of community policing (Sampson 2002). ${ }^{3}$

Linguists have shown more analytic ingenuity by grounding community in the grammar of inclusion and exclusion, demonstrating how expressions of solidarity and difference are contextualized in, for example, first person versus third person plural pronouns (we/they) or inclusive versus exclusive patterning (Duszak 2002; Skarzynska 2002; Scheibman 2004).

Just as significant, discourse analysts have developed Cohen's (1985) ideas on the symbolic construction of community and demonstrated how collective identity emerges in discursive action rather than being lodged in either static social facts or inner psychological states (Widdicombe 1998; Wodak et al. 1999). For Cohen (1985:118) community refers to a sociocultural sense of belonging and the symbolic construction of boundary, identity, and solidarity: "People construct community symbolically, making it a resource and repository of meaning, and a referent of their identity." And if community is a symbolic construction built on meaning and filtered through the lens of identity, then that construction occurs, to some extent, through language in and as social action. In this regard, Potter \& Reicher (1987:26) envision community as a discursive resource that participants mobilize for "description, evaluation and explanation"- that is, how speakers "categorize" community and frame symbolic boundaries through talk to construct social reality (see also Hester \& Housley 2002). ${ }^{4}$

\section{WHAT IS GEST URE?}

While linguistic and discourse studies analyze how participants orient to community in discursive interaction and thus avoid the reification pitfalls of their sociological counterparts, they still operate with a narrow conceptualization that equates 
discourse with verbal or written forms. However, McNeill $(1992,2005)$ and Kendon (2004) illustrate that speech and ad hoc hand gestures (or idiosyncratic hand gesticulations that generally though not invariably co-occur with speech) work together in the constitution of meaning and utterance construction. McNeill (2005) demonstrated that speech and gesture represent co-equal parts of language - the former conventional, segmental, and combinatorial, and the latter idiosyncratic, imagistic, and global (in which the meaning of the parts is determined by the whole). ${ }^{5}$ Kendon (2004) discovered how speech and gesture fulfill different yet complementary roles in the real-time synchronization of interaction and coexpression of meaning. Speakers continually adjust and readjust what he calls "speech-gesture ensembles" to achieve coherent courses of improvisational action and manage the on-line contingencies of producing turns at talk. Together, their findings offer a more robust understanding of how the visualization of meaning emerges through the mutual interplay of gesture-speech modalities.

From this initial work, the study of multimodal conduct or the integration of talk, gesture, and gaze has emerged as a vibrant and expanding research agenda (Stivers \& Sidnell 2005). Particularly relevant to the current project, several studies have examined how talk, gaze, and gesture are tightly organized and mutually elaborate one another to generate "coherent courses of social action" (Stivers \& Sidnell 2005:1). Goodwin (1986:41) demonstrated how speakers use gestures as a "point of visual" focus, directing the gaze of recipients to relevant aspects of the accompanying talk and, conversely, how gestures are made salient through gaze. Sidnell (2006) illustrated how speakers directed their gaze away from co-participants during reenactments in conversations (mimicking the speech and bodily conduct of the quoted speaker) and then returned gaze to recipients after completion of the enacted quote. The multimodal integration of gesture, gaze, and talk functioned to not only segment the narrative into distinct episodes but "elicit heightened displays of recipiency and attention" through shifts in footing and viewpoint (Sidnell 2006:405-6). Similarly, Sauer (2003) analyzed how miners switched between mimetic and analytic gestures when depicting dangerous events to authorize different viewpoints for affective and epistemic purposes. The miners used mimetic gestures and speech to place themselves inside the narrative and express their subjective experience; they used analytic gestures to convey an objective viewpoint as an outside observer toward the narrated events. As the miners switch between different viewpoints they simultaneously transform the relationship- "the rhetorical space" (Sauer 2003:260) — between themselves and their recipients. Both Mueller (2008) and Streeck $(1993,2009)$ examined how gaze directed at the hands possessed a pointing function that turns gesture into an "interactional significant object," a form of "multi-modal clustering" (Mueller 2008:237) that foregrounds certain information, especially when integrated syntactically into the stream of speech (Mueller 2008:234-38; Streeck 2009:98-104).

In this study, I describe how symbolic forms of social organization are not only talked but EMBODIED into being-instantiated in talk, gesture, and gaze as social 
action. I describe how forms of multimodal conduct are not mere affective ornamentation to linguistic modality but coordinate with talk to make meaning more vivid than would be the case by looking only at speech. ${ }^{6}$ Drawing on the research mentioned above, I show how bodily conduct adds another dimension to talk, how it foregrounds, reenacts, and authorizes symbolic associations, beats out the rhythm of utterances, and plots those rhythms onto deictic coordinates of space and direction. I analyze how gestures are not only turned into "interactionally significant objects" but, in the process, perform sociocultural context in converging streams of semiotic form.

\section{E T H N O R A P H I B A C K GROU N A N D D A T A}

The data for this study come from a transcription of a video-taped focus group session evaluating the effectiveness of community policing training. Focus groups are group discussions about a particular topic and are often used, along with more orthodox quantitative methods, as qualitative tools for assessing program effectiveness. They typically consist of a neutral moderator, who facilitates the discussion by asking questions on a given topic, and several interviewees, who provide their opinions on the topic (Myers 2004; Puchta \& Potter 2004). However, although moderators may initiate a topic, recipients do not necessarily talk on topic and even when they do, they do much more than address the topic at hand (Matoesian \& Coldren 2002; Matoesian 2005). Moreover, while focus groups possess interactive qualities like conversation, they are also more formal in the sense that speakers often - though not invariably - produce extended monologues with minimal interactive contributions from other participants, which is the case in the data for this analysis.

Here, the moderator is part of a community policing training institute from a large Midwestern university in one of the biggest cities in the United States; the interviewees are four police officers from a small rural town in a Southern part of the country and received training a few months previously. The fact that the "small town" trainees had strong negative opinions about the "big city" trainers stimulated much of the discussion about community in the ensuing data segments.

Community policing represents the new paradigm of policing: the major form of legal change and justice policy in the twentieth century. Maguire \& Wells (2002:33) refer to it as the most "significant area in police organizational change since the introduction of the telephone, auto and two-way radio," and Rosenbaum (2002:172) calls it the "new discourse of public safety among Western nations." Developed and sponsored by social science professionals, community policing attempts to reduce the alienating effects of police bureaucracy and remove professional detachment from the communities in which they serve. Using a discourse of partnerships, equality in decision making, and community involvement, it attempts to integrate police and community into a comprehensive model of crime control and thus mend the traditional opposition between them, especially in poor minority communities. This discourse of civic obligations envisions creating a sense of belonging in 
community through local neighborhood democracy, a democracy empowered through equal participation between police and citizens.

Of course, whether community policing actually integrates police and community or represents little more than a governmentalization of community - "a word used by government to infuse its methods of social control with a shiny caring veneer" (Studdert 2005:72) —is beyond the scope of this article. ${ }^{7}$

But rather than debate if community policing engineers a modern resurrection of small-scale community or invokes a nostalgic attempt to rebuild a sense of belonging or constitutes a "drama" or "rhetoric of control" (Manning 1988:29-31), I analyze how folk ideas of community circulate in and through multimodal form-how speakers index a sense of community and construct sociocultural boundaries in the synchronization of talk, gesture and gaze. Rather than view focus groups as a neutral medium or referential window to harvest information on a topic, I consider the multimodal practices of the interview before such practices get bleached from analytic scrutiny and domesticated into coding protocol.

In the next section, I analyze how a trainee's narrative not only describes but embodies community and police relations through an iconic integration of gesture, gaze, and syntax. I demonstrate how a multimodal ensemble of poetic discourse conveys abstract ideas more vividly than through verbal action alone, while it simultaneously enlivens those ideas by building an authoritative stance as the narrative progresses. As this occurs, the officer's multimetric motion of talk, gesture, and gaze displays not only the new spirit of unity between police and community but the strength of that unity. While the symbolic conception of community typically emphasizes maintaining boundaries between "us" and "them," it may also illuminate a felt unity between different groups. I show how the speaker projects the police as part of - even representative of - the community, dissolving the cleavage between them. Then I describe how academic experts that train police and community enter into the equation and how gesture, talk, and other forms of visible conduct combine to forge complex laminations of participation and novel configurations of cultural opposition and social solidarity. In a fascinating and densely layered narrative, this second police interviewee orchestrates mimetic gestures and sociodirectional space to plot the rhythmic coordinates of communal identity in an iconic interplay of multimodal action and social organization. The officer not only orchestrates a Gemeinschaft identity but does so under the auspices of maintaining symbolic boundaries and "policing" transgressions of those boundaries.

In each section, rather than treat community as a social fact or ideal type a la Tonnies or Durkheim, I consider how symbolic collectivities are embodied in the concrete details of what Streeck (2009:210) refers to as "improvisational gesture jazz"- "creative practices and skills" that figure in the production and interpretation of context. I consider the multimodal resources participants bring to bear on the sociocultural projection and performance of communal identity, solidarity, and opposition, that is, how a sense of social organization is instantiated in and as social action to accomplish distinct interactional work. 
WE'RE DOIN THIS HERE NOW: IN TEGRATING

GEST URE, GAZE, A N D S OCIOC ULT UR A L

C O N T E X T

The moderator begins the focus group session with the prototypic evaluation impact question: "How, if at all, did the relationship between the police and community change before and after the training, for better or worse?"

Immediately prior to the segment I analyze in detail below, one of the officer trainees (Officer One) stated his opinion about the training and academic trainers that set a critical atmosphere for the ensuing discussion:

I guess- my personal opinion was that they came down here thinking that (.) we were a small, almos- kind of (0.5) I hate to use the word (.) uh hick [derogatory term meaning rural, southern, or provincial - GM] town and we didn't know what we were doin and they had all the answers (1.0) I think we were doin pretty good before they ever came. We had officers walkin up and down the street, talking to shop owners.

In the aftermath of this critical assessment, Officer Two responds with the following narrative.

(1) Officer Two

((plain clothed detective at the opposite end of the table and to the left of the moderator))

1 We got away from that kind of stuff $y$ 'know:: (.) we the police $n$ they the

[

((gazing downwards toward the table with chin tucked in to the neck))

2 community (.) $N A::: W$

[

3 We-

((lateral head shake))

[

((hands move up from rest position in a parallel spread))

4 We're doin $=$ [

((gaze moves up toward hands + lateral sweep to bring hands together))

6 $=$ this here now

[

((tips of hands touch and hand clasp))

(.80)

[

((hands begin to spread open))

makin things strong

[

((open hands up and spread with palms parallel inward at head level))

((two quick up-down reverberations of the spread hands for emphasis))

8

9 gettin involved.

[

((rotation of right hand along elbow axis)) 
11 We have uh lot of police community relations and that's what it- what it is all

12 about.

In line 1, Officer Two directs gaze briefly at the moderator to signal the shift in speakership from Officer One and then redirects gaze back toward the table, looking downward with his left hand resting on the table and right hand positioned on the right thigh. His narrative begins with the first person institutional plural "We" (and past tense phrasal verb "got away") followed by the distal demonstrative and set-marking phrase ("that kind of stuff") without explicitly referring to what falls under auspices of the set. But we can infer that the reference involves a number of discontinued policing practices, such as unilateral decision making and bureaucratic detachment. Of course, pronoun reference is ambiguous. On the one hand, it could be the police who had "gotten away" from their traditional practices; on the other hand, it could refer to both the police and community who had gotten away from their traditional opposition to enter a new era of police-citizen cooperation. However, if we look back at Officer One's narrative, it appears that the second officer's "We" refers to the police.

The distal demonstrative + past tense in particular symbolizes a historically distant and abandoned practice some remove from the current speaking event and, as it turns out, what the police had "got away from" was the police-community opposition that materializes in the discourse marker " $y$ 'know" followed by the appositional phrase "we the police $\mathrm{n}$ they the community." Schiffrin (1987:267) noted that the discourse marker you know "marks the transition in information states which are relevant for participation frameworks and gain attention from the hearer." In this instance, Officer Two bolsters the significance of the information through a discretely juxtaposed type of contrastive opposition nestled in an intricate text-metrical format.

In lines 1-2 he signals the opposition through pronouns and unmarked plural nouns. The first person and third person pronouns, "we" and "they," describe ingroup versus out-group relations: the historical antagonism between police and community. ${ }^{8}$ Moreover, the opposition is embedded within a broader form of contrastive parallelism with repetition and variation anchored around the determiners in the apposition ("the police," "the community"). In so doing, he not only foregrounds the opposition but manipulates it to display social distance (Skarzynska 2002). By juxtaposing pronominal opposition for strategic affect, he animates how the police have relinquished traditional cleavages, voicing previously held sentiments as he simultaneously evaluates them not only through repetition but in vowel lengthening, stress, and increased volume on the negative affect marker "NA:::W" (Ochs \& Capps 2001:47). We can witness the crucial impact of multimodal conduct in concert with talk in line 2 as the negative interacts with a vigorous lateral head shake to intensify rejection of the traditional dichotomy - a noticeably marked emphatic stance. 
One further multimodal practice in line 2 warrants mention. As we saw previously, gaze often accompanies speech and gesture to build meaningful action and construct a sense of involvement in talk. According to Goffman (1963:43), "Involvement refers to the capacity of the individual to give, or withhold from giving, concerted attention to some activity at hand." In "we the police n they the community" in lines 1-2, Officer Two directs a middle-distance gaze (Goffman 1979:65) with a "chin tuck" in which the chin burrows into the neck - downwards towards the table (see Figure 1 below), a motionless show of disaffiliation from the old style of policing that becomes even more prominent, as we see below, when he shifts gaze and postural alignment in line 4.

In line 2, he recruits the negative affect marker and head shake as the multimodal ground to project a more richly textured tale of police-community relations in which the police and community have become a single unified group, a symbolic transformation that unfolds as follows.

First, in lines 3-5, his hands (with fingers extended upward at a slight angle) move up and outward from the "rest" or home position to coordinate a broad sweeping gesture that conveys perceptually salient information (see Figure 2): one hand represents the community, the other the police. He repositions head and gaze upward (notice the shift out of the "chin tuck" from Fig. 1 to Fig. 2) to align with movement of the hands toward their projected point of contact at the center

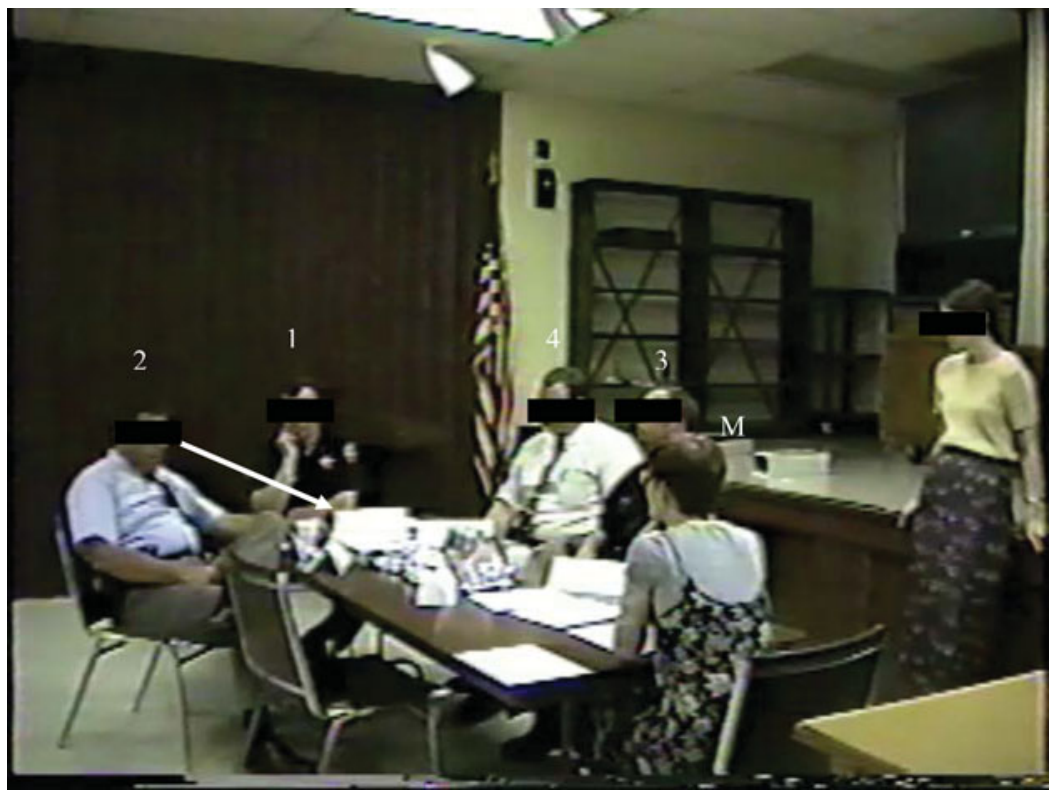

FIGURE 1. Lines 1-2: "We the police $n$ they the public" (Officers One-Four; $M=$ Moderator). 


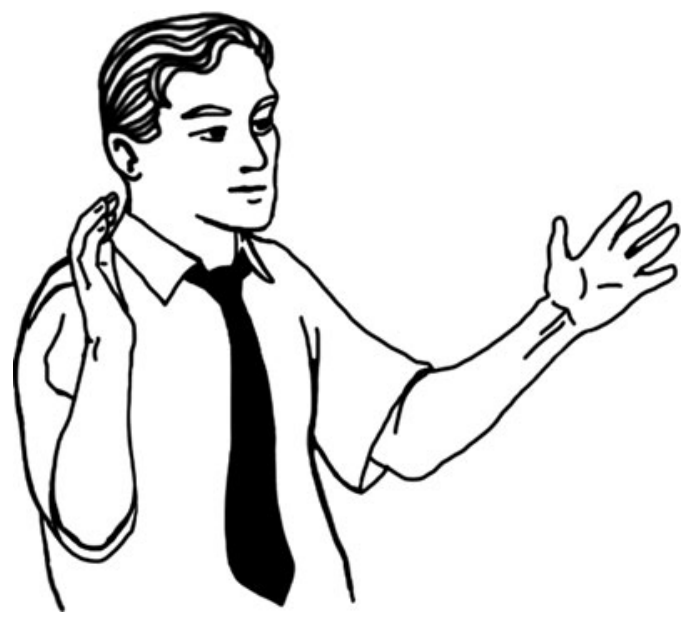

FIGURE 2. Line 4: "We're doin."

of attentional space, generating a heightened display of involvement (in sharp contrast with prior gaze direction at the table). The path + motion-encoding gesture creates a dynamic image of how far apart "we" and "they" were and the symbolic chasm to be traversed in uniting them.

Second, in lines 3-5 the verbal counterpart to the hands-in-motion gesture starts simultaneously with a cut-off repair "We-" followed by the first person plural and contracted copula "We're" + progressive verb (with final consonant cluster reduction) to indicate imperfective aspect. ${ }^{9}$ Additionally, the speaker expands the proximal demonstrative "this" with the deictic place adverb "here" and temporal deictic "now." Indeed, the deictic demonstrative allows other participants the opportunity to gauge distance and plot visually the point of contact between the converging hands. And it shows the contrastive opposition between the distal demonstrative in line 1 and the proximal demonstrative in line 5.

Third, multiple semiotic streams converge and merge at a climactic pulse in line 5. The hands-in-motion form a clasp gesture at onset of the deictic particle "this here now," aligning the individual digits in a tight fold (see Figure 3 below). When this occurs, the gesture integrates into the stream of speech as the object of deictic reference, where it synchronizes perfectly with gaze direction to become an interactionally significant object and visible focus of joint attention (Streeck 1993; Muller 2008). In this regard, Streeck (1995:103) notes: "A common way in which speakers solicit the audience's attention to a gesture is the use of a deictic particle which points to the movement."10 Following McNeill (1992), the hand clasp constitutes the stroke or meaning-bearing phase of the gesture. Moreover, the clasp is "frozen" or held in place for eight-tenths of a second in a post-stroke hold (McNeill 1992) to further accentuate its significance. Thus integration of 


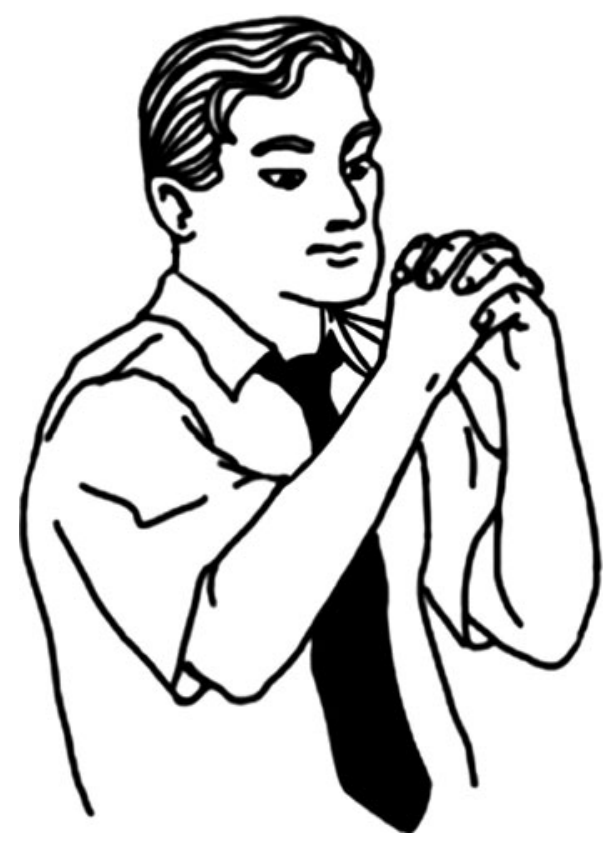

FIGURE 3. Line 5: "This here now."

multimodal actions in the form of speech, gesture, and gaze mutually elaborate one another in an iconic relationship between gestural form and, as I elaborate below, its referent.

Fourth, after the pause, the clasp decays, and the hands move apart to form another gesture, rejuvenating multimodal momentum in the process. As it turns out, the progressive and its gestural counterpart in lines 4-5 constitute the multimodal platform to launch a rhythmically infused lamination laid out in a slightly staccato strut, with repetition and variation not only in the progressives (each also with final consonant cluster reduction) and accompanying gestures but in the eighttenths of a second pause length between each utterance in lines 6,8 , and 10 . In line 7, Officer Two produces a gesture with the hands spread apart (and parallel) and palms open/turned inward and facing one another (in front of him at head level) that corresponds to the progressive "makin things strong" (see Figure 4). Moreover and for emphatic affect, the gesture occurs with two quick up-down reverberations in the hands as a post-stroke hold. After a second eight-tenths of a second pause in line 8 , the parallel structure closes with a third progressive verb "gettin involved" accompanied by a wrist/arm rotation gesture - another manner of motion gesture emphasizing continuous action in process-with a third .8 second pause (see Figure 5). As McNeill mentions (1992:159): "Metaphors for transitions or processes in general always seem to include some element of rotation: 


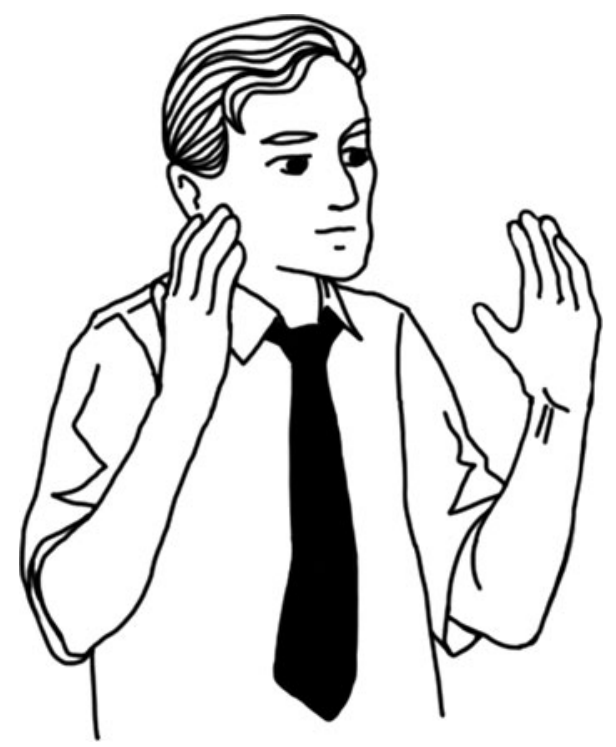

FIGURE 4. Line 7: "makin things strong."

the gesture conveys the transition as repetitive and/or cyclic, an image that appears to be based on rotating wheels or gears, although there are no wheels or gears." We see later how the "transition" to community policing presents a looming point of opposition in the focus group session.

Finally, if we consider lines 1-12 in more sociocultural detail, notice that the speaker's narrative not only integrates talk and bodily conduct to achieve a coherent course of social action. The integration between talk and bodily conduct stands in an iconic relationship-and this is how the gesticulation resembles its referentwith the police and community. In this dynamic recontexutalization of culture, Officer Two's multimodal conduct projects a transformation from the traditional police-community dichotomy to a unity, claiming to speak as a representative of the newly merged and unified community. Just as talk and bodily conduct blend into a unified communicative resource, so too do the police and community merge into a tightly bonded collective identity. ${ }^{11}$ The speaker's narrative is laid out in a densely organized form of multimodal parallelism-repetition of the motion gestures that accompany imperfective aspect and build to a crescendoto create a seamless integration of the historical antagonists. It orchestrates a finely articulated interplay between different yet compatible multimodal actions and sociocultural motifs. And it foregrounds an iconic integration of syntactic, paralinguistic, and bodily parallelism that instantiates and reproduces the sociocultural values of community policing, affiliating with new cultural practices by displaying a "certain overt engrossment" (Goffman 1963:43). ${ }^{12}$ 


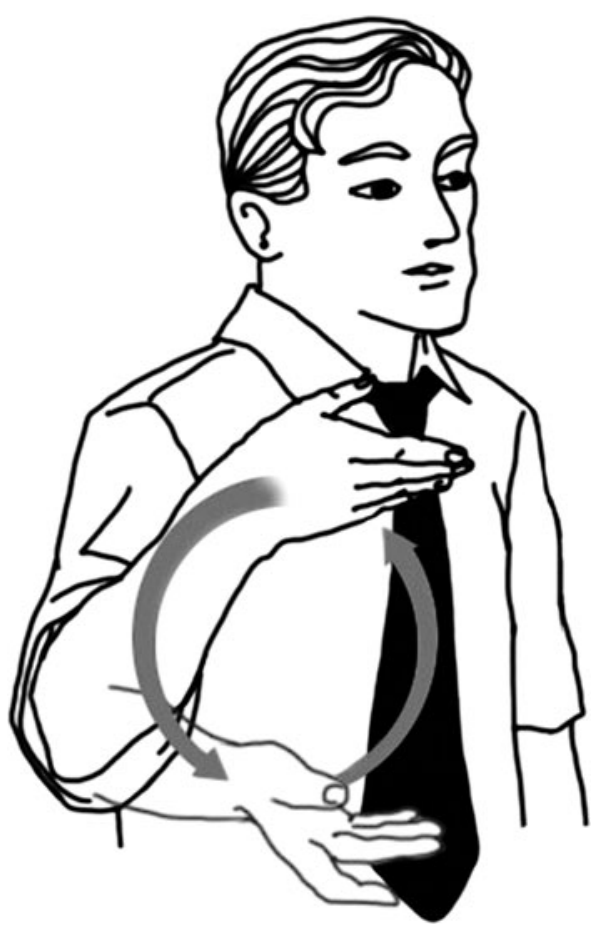

FIGURE 5. Line 9: "gettin involved."

The broad sweeping movement of the hands that culminates in the clasp offers a poignant illustration of how talk and bodily conduct mutually elaborate one another to index sociocultural context and instantiate a sense of communal identity. Just as the hands travel a significant distance to reach their clasp destination, so too do the police and community travel across historical space and time to dissolve the sociocultural boundary traditionally separating them, turning opposition into unity and projecting a symbolic merger between the two groups. Moreover, when gesture integrates syntactically into the stream of speech and synchronizes with gaze at the center of attentional space, it turns the utterance into not only an interactionally significant object but, even more importantly, a sociocultural resource that embodies and simultaneously enacts a sense of communal unity and togetherness, dissolving the cleavage between police and community. That is to say, "we're doing this here now" refers to the police and community as a unified communal identity, provides a new contextualization for abandoned practices, and, most importantly, talks and embodies community policing into being (at least according to Officer Two) as the gesture is made salient through the gaze-shift and deictic particle (see Goodwin 1986 and Streeck 1993). ${ }^{13}$ While the police may function as an 
autonomous bureaucratic organization, they need public support to fight crime. Just as the collective hand clasp is stronger than the sum of the individual digits, so too the police-community "partnership" provides a more potent crime fighting collective than the sum of individual parts.

Theoretically, the strength of each communicative modality complements and compensates for weakness of the other. As co-expressive semiotic resources, talk, gaze, and gesture mutually elaborate one another to enhance message content (Goodwin 2000:1499). ${ }^{14}$ To illustrate, why not merely state hypothetically, "We have traveled a great distance to unite the police and community and that journey constitutes a continuous process?" The clasp excursion constitutes what Müller (2008:237) calls a form of "multimodal clustering" in which the integration of gesture, gaze, and syntax draws attention to itself and provides a more vivid or imagistic representation than could be conveyed by words alone (or provides some aspect of meaning that could not be expressed as vividly). It builds a dramatic tension to the discourse that authenticates experience and crystallizes identity. ${ }^{15}$

The clasp and ensuing tightening of the interlocking digits offers what Kendon (1986) calls an "economy of expression" that exploits the multimodal division of labor between speech and gesture to enhance the context-specific contingencies of speaking. Each modality utilizes a communicative space that is best suited for conveying the message. Goldin-Meadow \& McNeill (1999:161-62) put it this way: "Given that gesture and speech convey meaning differently, it is possible for the meanings expressed in each of the two modalities to complement one another, creating a richer picture than the view offered by either modality alone. A speaker might not be able to convey a particular meaning in speech might well be able to express that meaning in gesture."

In sum, Officer Two's narrative coordinates an iconic interpenetration among talk, bodily conduct, and sociocultural context along several dimensions: (i) parallel structure integrating gestures that co-occur with imperfective aspect-marked utterances and paralinguistic pauses; ${ }^{16}$ (ii) integration of interlocking digits; (iii) integration of the interlocking digits into syntactic structure via the deictic particle and gaze direction; (iv) integration of the distal and the proximal demonstratives to represent historical opposition on the one hand and the current state of unity on the other; and (v) iconic integration of multimodal action and sociocultural context. Each integrative increment in the multimodal excursion contextualizes an interpretive frame for the next, which, in turn, reflexively recalibrates the prior as part of a continuous pattern, weaving an interlaced fusion of communicative modalities into a sociocultural whole. In the dynamic rhythms of visualizing and foregrounding meaning, the speaker aligns with the normative sentiments of community policing, a highly valued index of professionalism, while, quite ironically, disavowing those same professional boundaries in the interview context. In just this way, communal identity emerges as a contextually situated and multimodally emergent object in sociocultural space, an interactional resource embodied iconically and metaphorically in discursive form to accomplish distinct interactional work. ${ }^{17}$ 
In the next segment, we see how Officer Three dissolves the boundary between police and community but, in so doing, constructs another - highly antagonisticboundary in classic Gemeinschaft and Geselleschaft tradition.

\section{"H E Y B O B": S O C I A L O R G A N Z A T I O N I N \\ M U L T I M O A L Q U O T A T I O N}

(2) Officer Three (Uniform officer to immediate right of moderator)

$$
(\mathrm{B}-\mathrm{L})^{18} \quad(\mathrm{~B}-\mathrm{R})
$$

1 See (1.3) you can't have trainers from Chicago come South (0.5)

[

((gazing left at moderator))

2 to a small town to train small town people (0.6) big town ways

3 b'cuz it don't work (1.0)

[

((open palm))

4 I don't know (.) maybe it suggests that (0.4) > if this ever happens [

((back-forth horizontal gesture w/right hand at wrist axis))

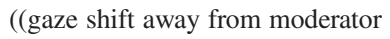

$$
\text { (B-R) (B-R) (B-R) }
$$

5 again $<$ you get small town trainers that know small town problems $(0.5)$

[

((gaze return to moderator))

6 b'cuz $>$ I mean- $<(($ sped up) $)(1.0)$ we call the

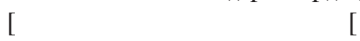

7 mayor Bob (0.6) y'know that's his name

8 "Hey Bob!

$$
\text { ((gaze returns to moderator)) }
$$

[

((gaze moves from moderator toward an "unoccupied" space))

((hand wave toward "Bob"))

9 How ya doin"

$$
\text { ( }
$$

10 Y'know I mean (.) that's how small and close that we are (.)

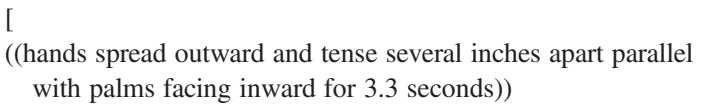

11 So::: a lot of the problems that they said we had we didn't have

$$
\text { [( }
$$

In the above segment, Officer Three resurrects the critical assessment of the trainers (mentioned previously by Officer One) in an elaborate form of contrastive 
opposition. To start, he links "Chicago" with "big town" and "South" with "small town" and amplifies the opposition in canonical contrastive pairs ("small town people big town ways") embedded in a strikingly nimble parallel structure. Additionally, he orchestrates the temporal flow of the utterance in a series of downward "hand chops" (Morris 1977) or rhythmic beats. ${ }^{19}$ According to McNeill (2005), nonrepresentational beats function as pragmatic "yellow highlighters" that parse significant segments of information for audience appreciation..$^{20}$

However, the beats here possess a densely layered format, one that departs significantly from McNeill's claim that they are nonrepresentational or lack semantic content. They not only conduct the temporal rhythms of speech but orchestrate the deictic coordinates of space, location, and direction as well. ${ }^{21}$ According to Haviland (2000:20) gestures not only point out absolute directions but may also index relative coordinates that reference speaker, audience, or "nonpresent objects."

In such cases "gestures literally create their referents to populate the illustrative gesturing space" (Haviland 2000:22). Notice how Officer Three beats with the right hand, and when he states "trainers from Chicago" the beat moves to his left and towards the focus group moderator (a good six inches or so). ${ }^{22}$ On the cardinal direction "South" and prepositional phrase ("to a small town" in line 2) both beats move to the right and align at the center of egocentric space (see Figure 6 below). At onset of the second compound adjective in line 2 ("big-town ways"), the beat moves once again to the left towards the moderator (see Fig. 6 below) and, after the down stroke, the officer forms an open palm display (in line 3) that accompanies "b'cuz it don't work"- doubtless designed for dramatic affect. In line 5, all three beats move to the right and align once again with the center of the officer's egocentric space. The first beat accompanies its lexical counterpart

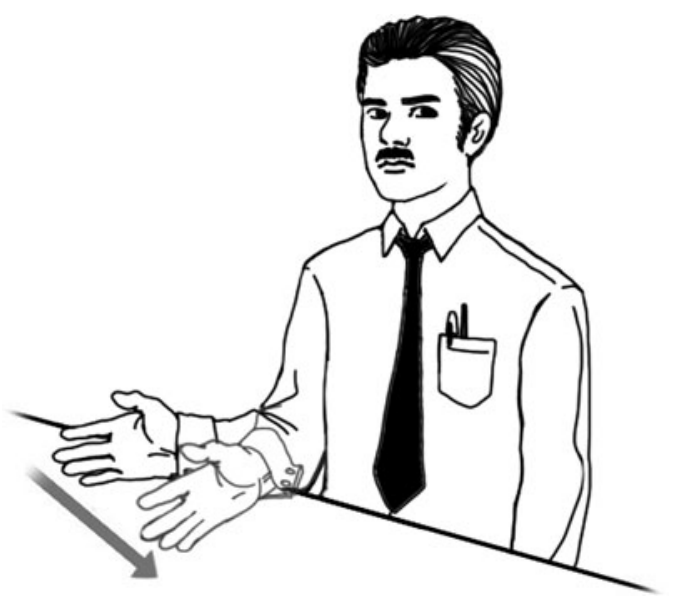

FIGURE 6. Line 2: "small town big town." 
over the entire compound ("small-town trainers") while the next two-short quick beats-co-occur with the compound adjective ("small-town problems"). In so doing, talk and the accompanying beats create relative spatial orientations by rotating (or substituting) the moderator and officer as imaginary reference points for the directional coordinates (for "big town" and "small town").

And there is more. Officer Three exploits the table as the material infrastructure for plotting out spatial coordinates and beating these into sociocultural significance. Each beat accompanies a lexical member of the contrast, foregrounding key dimensions of spatial opposition ("trainers from Chicago," "South," "small town," "big town") by calibrating and recalibrating direction via gestural movement. ${ }^{23}$ In a burst of spontaneous improvisation, the officer generates a metaphoric representation of sociocultural context that emerges in the interpenetration of rhythmic beats and spatial deictics. He deploys spatial-directional coordinates as neither extradiscursive reference nor cardinal direction (at least not primarily) but uses them in concert with rhythmic hand movements to accomplish distinct interactional work: to map the symbolic boundaries of cultural opposition (the moderator/trainers from "big town/Chicago," "people" from "South/small town"). ${ }^{24}$ Following Haviland (2000; see also Streeck 2009:79), spatial points of reference are deictically anchored relative to not only (or even primarily) the officer and moderator but to their sociocultural significance in the transposed narrative space. Rather than consider beat, deictic, iconic, and metaphoric gestures as discrete categories, we may wish to consider how novel gestural configurations emerge in and function through multimodal interaction. ${ }^{25}$

Following the parallel structure in line 5, "you get small town trainers that know small town problems," Officer Three provides grounds for the recommendation through a multi-laminated shift in footing and participation (lines 6-9). Goffman (1981) developed the concept of footing to refer to the speaker's relation to and involvement with their talk: the animator produces the words, the author composes them, and the principal authorizes those words as the responsible party. Goodwin \& Goodwin (2004) expanded the concept to include not only language but forms of embodied conduct in the dynamic emergence of micro forms of social organization or participation, a point relevant to the social actions under analytic scrutiny here.

With the above points in mind, notice Officer Three announces that they address the mayor with first name reference "I mean we call the mayor Bob"26 — nickname reference in fact - rather than the more formal role label or role label plus last name. From the infinite possibilities to refer to the mayor the speaker chooses one in particular and bolsters the relevance of such reference by enclosing it within two discourse markers: "I mean" and "y'know."27 Schiffrin (1987:268) found that both y'know and I mean work on the participation structure of talk. As noted earlier, $y$ 'know signals to the hearer that a given claim is "generally known" or noncontroversial, encouraging hearer agreement. I mean functions, first, to contextualize expansion of a prior piece of information, and, second, to signal that a new form of participation is imminent (Schiffrin 1987:308-9). 
And we can witness the relevance of both markers in lines 7-10. In line 7, just prior to "y'know," the speaker shifts gaze and orientation back to the moderator. In line 8 , he shifts participation structure and footing through performance of a MULTIMODAL QUOTE organized as follows. He redirects gaze - coupled with a marked eyebrow flash-from the moderator toward an "unoccupied" space between fellow officers to his right and moderator to the left. At the same time, he produces a direct quote ("Hey Bob") - with noticeably marked stress and increased volume - synchronized with a hand wave toward the virtual space in Figure 7 below (the hand positioned upward and palm outward toward the imaginary mayor to produce an informal wave for an informal address). The wave does not rotate laterally around the wrist or elbow axis but consists solely of bent-at-the-elbow upward arm extension. As the wave decays he expands the verbal greeting post vocative with deletion of the copula in line 9, "how ya doin?," still maintaining postural and visual alignment toward the deictic space in this informal greeting register. At completion of the reenactment, he returns gaze back to the moderator. In the process, we can see how bodily conduct in the form of gaze and gesture segment different parts of the narrative (Sidnell 2006). We can see too the crucial interaction between the person-reference description in lines 6-7 and the ensuing multimodal quote. When the officer identifies the mayor as Bob (in lines 6-7), his description functions as a metapragmatic frame that contextualizes reference in the quote.

In line 10, both markers occur adjacent to one another at turn onset where they preface "that's how small and close that we are (.)" (see Figure 8) and accompany a gesture (in which the hands are held in a parallel position with the palms facing one another) to emphasize the closeness of the community. Notice also how the fingers

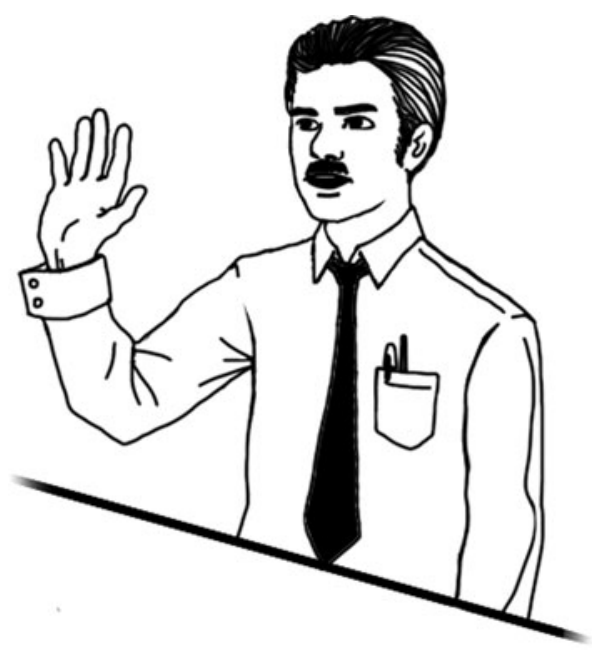

FIGURE 7. Line 8: "Hey Bob!" 


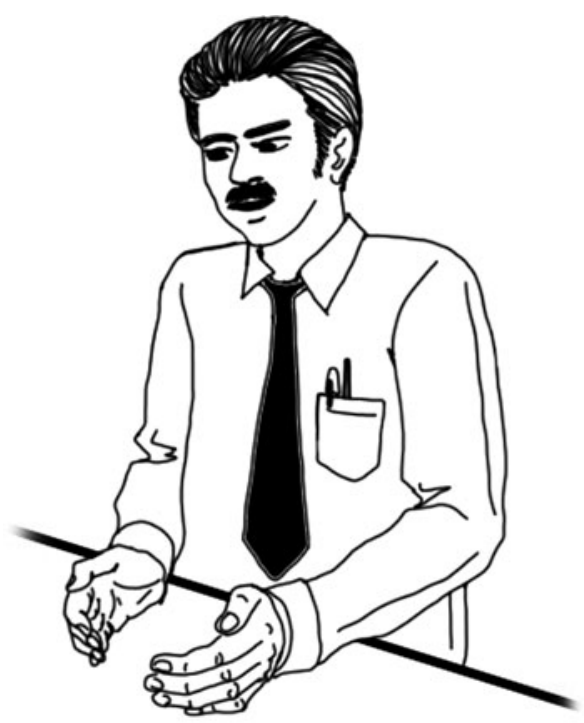

FIGURE 8. Line 10: "that's how small and close that we are."

are spread out in a "tensed" position for emphasis and frozen in a post-stroke hold for over three seconds.

What does the multimodal quote convey beyond the prior and post descriptions? What does the gesture accomplish that "we call our mayor Bob" and "that's how small and close we are" do not?

First, as mentioned previously, Sidnell (2006) and Sauer (2003) demonstrated how speakers alternate between reenactments and descriptions of actions, actors, and events to accomplish distinct interactional work in narratives. Sidnell (2006) discovered that speakers withdrew gaze from co-participants during verbal and bodily reenactments and returned gaze to them upon completion to "show not what someone witnessed (or heard about) but rather what happened," creating an authoritative and objective epistemic stance toward the events depicted. Sauer (2003:229) found that speakers used speech and embodied conduct mimetically to reenact actors, actions, and events as if they were "present at the scene they describe." In contrast, they used analytic viewpoints to signal a more detached perspective "outside of the speaker's direct sensory and emotional experience" (Sauer 2003:239). In the same way, Officer Three's "Hey Bob" mimetic reenactment demonstrates that he is in an epistemological privileged position to know how "we" call the mayor while his "that's how small and close we are" description provides an analytic viewpoint of the reenactments abstract relevance. ${ }^{28}$ Indeed, the description plus reenactment function in a type-token interplay that legitimates and authorizes the speaker's epistemic stance, linking analytic type "that's how small" to 
mimetic token "Hey Bob" while simultaneously foregrounding the gestalt-like significance of each: extrapolating inferences from token to type and type to token.

Second, we have seen how verbal and visual quotes create a visual trajectory toward, and populate a virtual space with, the nonpresent mayor, decontextualizing prior multimodal actions and recontextualizing them into the current speech event. But the speaker does quite a more than report prior multimodal conduct; he does more than transpose the historical greeting into the current speech event. When the officer populates a virtual space for the mayor, he contextualizes another lamination of participation in which to imagine a reciprocal wave and first-name greeting from the mayor to the officer(s). ${ }^{29}$ The speaker not only creates a virtual space populated by the nonpresent mayor but circulates a transposed frame for a reciprocal greeting space that pulls the audience into a state of deictic immediacy with it. That is to say, the multimodal quote establishes a visual focus of attention for the reported event and enlivens "Bob" in the current speech event, a feat that neither the verbal description nor verbal quote could accomplish on its own - at least not as vividly. ${ }^{30}$

This interdiscursive drive for reference reveals how talk and bodily conduct function as complementary resources the speaker brings to bear on the symbolic construction of community and networks of virtual interaction. Officer Three describes how the police (and quite possibly citizens) address the mayor in his community while simultaneously ENACTING Gemeinschaft solidarity in contrast to Gesellschaft formality, endowing his performance with epistemic authority and revealing how collective identities and sociocultural boundaries emerge interdiscursively in multimodal form. ${ }^{31}$ Referring to the mayor as "Bob" foregrounds how formal rational structures are subordinate to the informal norms of the community - to the familiar bonds of sociality over the post-modern fragmentation and impersonal bureaucratization of social life. Just as crucial, Officer Three displays that he (and other officers/citizens) not only knows the mayor's first name but also has the right to use that address and expects a first name greeting from the mayor in return, indexing cultural values - individuals interacting with one another on a personal basis - in a perfectly balanced alignment of gesture, gaze, and talk. ${ }^{32}$ His multimodal excursion recruits an imaginary form of participation that furnishes the interpretive resources to imagine an imaginary performance in this imaginary Gemeinshaft community.

And last, sameness and difference in linguistic, stylistic, and embodied practices naturalize sameness and difference in sociocultural context (e.g. small town people big town ways and Hey Bob). Cultural opposition emerges in and through a complex interpenetration of grammatical, stylistic, and bodily resources that become "iconic representations" of social differentiation (Gal \& Irvine 1995). As Gal \& Irvine (1995:970) state: "Linguistic practices that index social groups or activities appear to be iconic representations of them - as if a linguistic feature somehow depicted or displayed a social group's inherent nature or essence." In the case here, the speaker draws on a linguistic ideology in which difference and sameness in communicative practice project difference and sameness in sociocultural context and 
naturalize those differences in multimodal form (see Silverstein 1979). Silverstein $(1979,1993)$ has demonstrated that direct quotes project grammatical and metapragmatic forms onto extralinguistic reality, naturalizing referential value over strategic meaning to generate an epistemologically privileged dialogue of voices. Perhaps multimodal quotation, by virtue of mapping another modality onto the reporting voice, amplifies that projection onto extra linguistic reality.

We have examined how the complex integration of talk, gesture, and gaze functions in this legal setting and how multimodal practices construct collective emblems of our social selves. But thus far we have operated with a rather simplistic and unitary view of culture, and it is time to consider how criss-crossing circuits of sociocultural context operate simultaneously over the same oppositional terrain. We have seen how Officer Two dissolves police-community opposition by creating a unity, offering himself as representative of the community, while Officer Three not only dissolves opposition but rechannels it from police-community to big city-small town. In a rather ingenious maneuver, Officer Three removes the traditional opposition - the topic of the focus group evaluation impact assessment-by creating a new one! He displaces blame canonically directed to the police and reallocates it to the institute trainers. Although community policing emerged in critical response to unilateral decision making and bureaucratic detachment on the part of the police, the new emerging conflict-symbolic, real, or in-between - reveals a radical transformation of institutional identities and practices as Officer Three accuses big-city trainers of possessing the same negative traits historically attributed to the police, such as unilateral decision making (in line 11): "So::: a lot of the problems that they said we had we didn't have." ${ }^{33}$ His open-palm gesture mapped onto the assessment offers a sigh of exasperation at the trainer's bureaucratic indifference to the local needs of their community.

More speculatively, the above process implicates another sociocultural conflict: a thinly veiled allusion about command of professional knowledge and the social power it confers. Here crisscrossing streams of sociocultural relevance unfold incrementally and progressively as the police "police" the integrity of their expert authority and guard against interprofessional incursion. Recall how Officer Two's (refer back to Officer One also) narrative suggested that the police beat the institute to the punch, as it were, engaging in community policing prior to academic intervention. ${ }^{34}$ But Officer Three organizes a more allusive attempt to realign expert-novice participation roles, a realignment in jurisdictional control between police traineeswho feel that they are the experts on policing — and academic trainers — who receive large grant dollars but possess no hands-on experience in policing.

In lines 1-3, Officer Three produces an emotionally textured assessment of the training that culminates in the lack of agreement for an emphatic stance: "it don't 
work." However, in lines 4-5 he delivers a recommendation prefaced with a litany of hedged stance markers - at least on the surface: the "I don't know" epistemic clause accompanied by a horizontal flip-flop of the right hand along the wrist axis, followed by the epistemic adverb "maybe," epistemic verbal "suggests" and conditional "if this ever happens again." 35 Why the flip-flop in epistemic stance marking? ${ }^{36}$

That the officer experienced training first-hand would qualify him to assess its outcome and thus provide grounds for the emphatic "it don't work"- at least in his small community. By contrast, academic trainers represent the experts on community policing training in general, and the modulated stance marking may defer to their professional expertise in this regard. But notice the officer uses 3rd-person "it" as the subject of the epistemic verb, which, in turn, controls the that-clause. That is, Officer Three does not suggest the recommendation (as in hypothetically, "I suggest") but "it" does, and "it" refers back to his prior emphatic stance. Rather than offer a recommendation based on mere subjective opinion, the officer smuggles in an objective fact about the training not working burrowed under the auspices of a modestly tempered stance. A deft polyphonic movement, the agentless passive "It suggests" may well convey a degree of uncertainty, but it simultaneously indexes, in this case, the objective facticity of "independent" evidence by obscuring agency (Ehrlich 2001:47-49) — evidence that just happens to be the officer's opinion. Flip-flop gesture and flip-flop stance set into play an ambivalent dialectic in which gesture and talk naturalize one another in a hybrid blend of subjective opinion and objective fact.

There is an interesting multimodal feature of Officer Three's narrative in the conditional ("if this ever happens again" in lines 4-5). He contextualizes realignment in participation roles and activity structure through noticeably marked shifts in pitch register, gaze direction and posture on the conditional. At the .4 pause, he (i) jerks the head upward and back, (ii) redirects gaze — with a marked eyebrow flash — from the moderator to the other officers situated to his right, and (iii) lowers the volume and speeds up the rate of speech to suggest that "this won't ever happen again but only us officers know it": a subterranean form of participation with a subtle yet highly partisan aura of involvement. ${ }^{37}$ That is to say, he marks a discursive boundary via the shift in participation - using gaze and postural shift to contextualize the insult or rejection of the trainer's expertise - as a metaphoric lamination for how the police "police" interprofessional boundaries (or, more prosaically, boundary marking within boundary marking). Although both moderator and other officers are addressed recipients in the verbal component they stand in a differentially positioned multimodal alignment that corresponds to differentially distributed forms of knowledge based on privileged access to in-group membership: other officers are primary recipients, the moderator a secondary recipient. In a subtle form of "collusive by-play" (Goffman 1981:134), we see a vivid interpenetration of situated, professional and cultural identities that produces an in-group versus out-group metaphor IN-MOTION. 
Thus while recommendations for future training appear couched in a tentative epistemic stance - at least based on grammatical marking - they inject much more certainty into the officer's stance when considered multimodally. They reset the expert-novice form of participation to elevate the officer's status relative to the academic trainers and resurrect — to some extent — the symbolic boundaries of professional expertise. ${ }^{38}$

\section{O N C L U S I O N}

If community is, as some suggest, the most important concept in sociology and doubtless important for social science more generally, then it should be meaningful to and relevant for the participants of a given community. If Gemeinschaft community incorporates speaking in one voice, then we have seen an index of that, as a unified chorus of discursive solidarity emerges in the wake of each officer's response - in the multimodal discourse of exclusion and inclusion. ${ }^{39}$ While the moderator poses a rather explicit and succinct topic, the focus group officers disregard it and assert the relevance of their own topic, incrementally and progressively escalating in-group versus out-group differences in hierarchical laminations of communal relations and professional status.

Consequently, rather than consider community as an ideal type or imagined reality or statistical aggregate, I have shown how speakers bring an array of communicative resources to bear on the constitution of identity and lamination of sociocultural context: a multimodal, multiparty, and interactive dialogue of communal and professional voices. Methodologically, the argument is made frequently that positing such macro-micro links obscures the workings of the interaction order. I eschew such general rules and prescriptive recommendations to see what the individual case offers analytically. While beats, for example, have often been associated more with pragmatic structure than semantic or referential content, we have witnessed how novel metaphoric representations emerge through the integration of multiple semiotic streams as they converge on a strategic discursive task. I have shown-indeed the participants have shown - not only how a symbolic sense of community is performed in the situated details of multimodal form but how, in the process, novel forms of gestural meaning may emerge that might otherwise have gone unnoticed. 


\section{A P P E N D I X: T R A N S C R I P T I O N C O N VEN T I O N S}

Adapted from Stivers \& Sidnell (2005).

[ marks the position where talk co-occurs with gesture, gaze, or posture

(( contains the type of bodily conduct co-occurring with talk

(.4) indicates seconds and tenths of seconds

$::$ indicates vowel or sound stretching

- $\quad$ symbolizes a cut-off

italics indicates stress

bold marks increased loudness

$>\quad$ Sped-up utterance

$=\quad$ indicates immediately latched utterances

\section{N O T E S}

*Thanks to Susan Gal and Michael Silverstein (as always) along with their students at the Semiotics Workshop at the University of Chicago; David McNeill and Susan Duncan along with their students at the University of Chicago Mini-Conference to Honor Adam Kendon; Adam Kendon, Adam Jaworski, Lisa Frohmann, and Mindie Lazarus-Black for all their help, encouragement, and advice. I owe a special debt of gratitude to Jennifer Huiying Qian for her skill in doing the sketches. Finally, thanks to Barbara and the anonymous reviewers for their constructive criticism and recommendations for improving the article.

${ }^{1}$ Norris (2004:9) finds that "All interactions are multimodal" by which she includes "proxemics, posture, head movement, gesture, gaze, spoken language."

${ }^{2}$ Some (quite famous) sociologists claim that community is the "most sociological of all topics" (Erickson 1978:13).

${ }^{3}$ From 1995-1999 President Clinton and the United States Congress budgeted six billion dollars for community policing programs (US Department of Justice COPS Press Release, Feb 14, 2000).

${ }^{4}$ Even prior to Cohen's work and studies inspired by it, Atkinson \& Drew (1979) illustrated how location descriptions functioned as interactional resources for constructing moral inferences about hostile religious communities.

${ }^{5}$ More accurately, iconic and metaphoric gestures are more imagistic while others orchestrate the rhythmic patterning of utterances (beats) or point out objects in real or imaginary space (deictics). The distinction is more dimensional than categorical as we see later.

${ }^{6}$ For both McNeill and Kendon, gestures (or gesticulations) refer to idiosyncratic hand movements that co-occur and are made meaningful with speech. This distinguishes gesticulations from emblems or quotable gestures and sign languages that operate with varying degrees of conventional formmeaning relations. They also distinguish gesticulations from other forms of bodily conduct such as gaze and postural orientation, which, according to Kendon (2000:49) function "in the processes by which participants in interaction establish and maintain their orientations to one another." While this study focuses primarily on gesture in the McNeill/Kendon sense, I look more broadly at the integration of talk with gesture and other forms of multimodal conduct.

${ }^{7}$ This is not to say, of course, that the governmentalization of community is irrelevant, for there are a host of new discourses of community in vogue. Day (2006:14) writes that "community can be used as a tag-word to confer a positive aura upon notions which might otherwise seem unattractive- like "community policing', 'community discipline' or practices like neighborhood watch."

${ }^{8}$ Scheibman (2007:128) states: “"They' indexes a class of people with social and institutional relevance who are viewed derisively." 
${ }^{9}$ It appears that the cut-off repair on "We-" functions here, following Kendon (2004), to maintain the integrity of the gesture-speech ensemble.

${ }^{10}$ According to Müller (2008:236-37) speech-framed gestures that complete utterances are significant for the audience: "For the co-participants this is not to be missed, because the gesture carries semantic information that is not provided verbally - it completes this part of the utterance."

${ }^{11}$ Streeck (2009: 168-70) discusses a similar case of "enmeshment" or "interlocking of all the fingers of the two hands" as a metaphor for "lack of ego-boundaries." In much the same way, Officer Two's enmeshment functions as a metaphor for removal of the symbolic boundary separating community and police. That is, rather than a lack of ego boundary, we see a lack of group boundary.

${ }^{12}$ In sharp contrast to the motionless show of disaffiliation from old practices seen in line 1 .

${ }^{13}$ While the clasp is not, formally, what McNeill (2010) refers to as a "speech framed gesture" that stands alone and "fills a grammatical slot," it has the "feel" of standing alone (at least to me in any event). And that appears to intensify the foregrounding affect it possesses. Relatedly, Müller (2008:238) provides an excellent illustration of how the integration of gaze and gesture into syntactic structure "foregrounds verbal metaphors."

${ }^{14}$ According to McNeill (2005:22) speech and gesture are "co-expressive but not redundant; gesture and speech express the same underlying idea unit but express it in their own ways."

${ }^{15}$ Of course, both the deictic particle "this here now" and indexing gesture (hand clasp) are only interpretable when working together. There is no way to understand one without the other.

${ }^{16}$ Still more technically, Duncan (2002) has shown how gestures vary in their degree of complexity and duration relative to aspect. Imperfective aspect as in doin, makin, and getting is accompanied by gestures that are iconic, more complex, and of greater duration than gestures co-occurring with perfective aspect.

${ }^{17}$ More logically, Officer Two conveys the inference that (i) if the symbolic boundary between the police and community has been breached and unity restored; (ii) the police and community constitute the same entity; and if this is so then (iii) community policing training is redundant in the sense that "we are already doing it."

${ }^{18} \mathrm{~B}-\mathrm{L}=$ beats toward left; $\mathrm{B}-\mathrm{R}=$ beats toward right

${ }^{19}$ According to Morris (1977:58), these occur with the "straight hand rigid and slashed downward as if slinging through verbal clutter." In this case they not only slash but (literally) bounce off the table on each downward stroke.

${ }^{20}$ See Streeck (2008) for a fascinating and in-depth analysis of beats in political discourse.

${ }^{21}$ As Jaworski \& Thurlow (2009:254) state: "Deictic gestures may indicate persons, objects, directions or locations, or may 'point to' nonexistent or imaginary referents."

${ }^{22}$ The focus group moderator in this instance happens to be more than mere moderator. She is also in charge of the institute's training and trainers, and the officers know that.

${ }^{23}$ The use of "South" here does refer to cardinal direction, at least in a literal sense, but it is also being used with a slang or indirect meaning consisting of a not too subtle invidious comparison between urbansuperior and rural-inferior (or worse).

${ }^{24}$ Notice that Officer Three never makes reference to the police but to "small town people" (line 2).

${ }^{25}$ More recently, McNeill (2005:41) claims that semiotic properties like deixis, beats, and the like are "dimensional and not categorical" and that "we often find iconicity, deixis and other features mixing in the same gesture." The term I prefer to use here is "emergent." See the discussion of this in Jaworski \& Thurlow (2009:254) also.

${ }^{26}$ The unspecified 1st person plural "we" here presumably refers to the officers since he shifts gaze toward them.

${ }^{27}$ One other feature bolsters the impact of the first person plural here. Scheibman (2007:129) shows how use of such generalizations functions in stance taking: "expanding the reach of an assertion in conversation using a generalization can potentially increase the expressive power or authority of that assertion."

${ }^{28}$ As Sauer (2003:221) mentions: "Analytic viewpoints represent abstract processes, objects and conditions that would be literally beyond the reach of human perception," and "that's how small and close we are" would be a perfect illustration. 


\section{GESTURE’S COMMUNITY}

${ }^{29}$ And given the ambiguity of "we" it is also possible to imagine not only other officers engaged in reciprocal first-name greeting exchange with the mayor but other citizens also, especially since, as mentioned previously, Officer Three never makes reference to the police but only to "small town people."

${ }^{30}$ Just as interesting, the four incremental references to Mayor Bob function as evidential tokens of "how close we are."

${ }^{31}$ The idea of interdiscursivity is most relevant here. Faudree (2009:154) states that "interdiscursivity refers to continuity across speech events and hence to stability rooted in persons or TYPES OF PERSONS" (my emphasis).

${ }^{32}$ The substitution of "Hey" for "Hi" would also index a more informal greeting address.

${ }^{33}$ Another striking illustration of this occurred when Officer Four (the other plain-clothed detective in the pictures) complained that the trainers just "wanted to talk about gang problems but we don't have gang problems." He went on to assert that "we have the highest teen pregnancy rate in the state but they [i.e. the trainers] didn't want to talk about that."

${ }^{34} \mathrm{An}$ ethnographic observation warrants mention here. The police in this community were the only group of trainees to quit and ask the institute to leave. Why, then, did the officers agree to participate in the training in the first place? In the focus group interview one of the officers mentioned that the only reason they agreed to participate in the first place was because they had been ordered to by the chief of police.

${ }^{35}$ As well as the two short pauses in line 4.

${ }^{36}$ Of course, the epistemic markers, especially "I don't know" epistemic clause, could delay and project a negative assessment or evaluation as well.

${ }^{37} \mathrm{Put}$ more prosaically, it looks and sounds as if Officer Three is speaking out of the side of his mouth, both literally and figuratively. As this happens, he produces a vivid illustration of what Silverstein (1997:266) refers to as a "mapping of interactional text onto denotational text," such that what we are saying EVEN NONVERBALLY becomes what we are doing now (Silverstein, p.c.).

${ }^{38}$ Quite ironically, this also proves the point about community policing in general: that the police are often the ones most resistant to change!

${ }^{39}$ While we have only focused here on two of four officers, Officers One and Four are just as critical of the institute's training, perhaps even more so. See n. 29.

\section{R E F E R E N C E S}

Atkinson, J. Maxwell, \& Paul Drew (1979). Order in court. New York: Macmillan.

Bauman, Zygmunt (2001). Community. Cambridge: Polity.

Cohen, Anthony (1985). The symbolic construction of community. London: Routledge.

Day, Graham (2006). Community and everyday life: London: Routledge.

Duncan, Susan (2002). Gesture, verb aspect, and the nature of iconic imagery in natural discourse. Gesture 2:183-206.

Duszak, Anna (2002). Us and others: An introduction. In Anna Duszak (ed.), Us and others: Social identities across languages, discourses and cultures, 1-28. Philadelphia: John Benjamins.

Ehrlich, Susan (2001). Representing rape. New York: Routledge.

Erikson, Kai T. (1978). Everything in its path: Destruction of community in the Buffalo Creek flood. New York: Touchstone.

Faudree, Paja (2009). Linguistic anthropology in 2008: An election-cycle guide. American Anthropologist 111(2):153-61.

Gal, Susan, \& Judith Irvine (1995). The boundaries of language and disciplines: How ideologies construct differences. Social Research 62:967-1001.

Goffman, Erving (1963). Behavior in public places. New York: Free Press.

(1979). Gender advertisements. New York: Harper \& Row.

(1981). Forms of talk. Philadelphia: University of Pennsylvania Press. 


\section{GREGORY MATOESIAN}

Goldin-Meadow, Susan, \& David McNeill (1999). The role of gesture and mimetic representation in making language the province of speech. In Michael Corballis \& Stephen Lea (eds.), The descent of mind, 155-71. New York: Oxford University Press.

Goodwin, Charles (1986). Gestures as a resource for the organization of mutual orientation. Semiotica 62:29-49.

, (2000). Action and embodiment within situated human interaction. Journal of Pragmatics 32:1489-1522.

— \& Marjorie Goodwin (2004). Participation. In Alessandro Duranti (ed.), A companion to linguistic anthropology, 222-44. Oxford: Blackwell.

Haviland, John (2000). Pointing, gesture spaces and mental maps. In David McNeill (ed.), Language and gesture, 13-46. New York: Cambridge University Press.

Hester, Stephen, \& William Housley (2002). Introduction: Ethnomethodology and national identity. In Stephen Hester \& William Housley (eds.), Language, interaction and national identity, 1-15. Burlington, VT: Ashgate.

Jaworski, Adam, \& Crispin Thurlow (2009). Gesture and movement in tourist spaces. In Carey Jewitt (ed.), The Routledge handbook of multimodal analysis, 253-62. London: Routledge.

Kendon, Adam (1986). Some reasons for studying gesture. Semiotica 62:1-28.

(2000). Language and gesture: Unity or duality? In David McNeill (ed.), Language and gesture, 47-63. New York: Cambridge University Press.

(2004). Gesture. New York: Cambridge University Press.

Maguire, Ed, \& William Wells (2002). Community policing as communication reform. In Howard Giles (ed.), Law enforcement, communication and community, 33-66. Philadelphia: John Benjamins.

Manning, Peter (1988). Community policing as a drama of control. In Jack Green \& Stephen Mastrofski (eds.), Community policing: Rhetoric or reality, 27-45. New York: Praeger.

Matoesian, Gregory (2005). Struck by speech revisited: Embodied stance in jurisdictional discourse. Journal of Sociolinguistics 9:167-94.

— \& James Coldren (2002). Language and bodily conduct in focus group evaluations of legal policy. Discourse and Society 13:491-515.

McNeill, David (1992). Hand and mind. Chicago: University of Chicago Press.

(2005). Gesture and thought. Chicago: University of Chicago Press.

(2010). Gesture: A psycholinguistic approach. In Patrick Hogan (ed.), The Cambridge encyclopedia of the language sciences, 344-46. Cambridge: Cambridge University Press.

Morris, Desmond (1977). Manwatching. New York: Abrams.

Müller, Cornelia (2008). What gestures reveal about the nature of metaphor. In Alan Cienki \& Cornelia Müller (eds.), Metaphor and gesture, 219-45. Philadelphia: John Benjamins.

Myers, Greg (2004). Matters of opinion. New York: Cambridge University Press.

Neal, Sarah, \& Sue Walters (2008). Rural be/longing and rural social organizations: Conviviality and community-making in the English countryside. Sociology 42:279-97.

Norris, Sigrid (2004). Analyzing multimodal interaction. New York: Routledge.

Ochs, Elinor, \& Lisa Capps (2001). Living narrative. Cambridge, MA: Harvard University Press.

Potter, Jonathan, \& Stephen Reicher (1987). Discourses of community and conflict. British Journal of Social Psychology 26:25-40.

Puchta, Claudia, \& Jonathan Potter (2004). Focus group practice. London: Sage.

Rosenbaum, Dennis (2002). Evaluation in multi-agency anti-crime partnerships. Crime Prevention Studies 14:171-225.

Sampson, Robert (2002). Transcending tradition: New directions in community research, Chicago style. Criminology 40(2):213-30.

Sauer, Beverly (2003). The rhetoric of risk: Technical documentation in hazardous environments. Mahwah, NJ: Lawrence Erlbaum. 


\section{GESTURE'S COMMUNITY}

Scheibman, Joanne (2004). Inclusive and exclusive patterning of the English first person plural: Evidence from conversation. In Michel Achard \& Suzanne Kemmer (eds.), Language, culture and mind, 377-96. Stanford, CA: CSLI Publications.

(2007). Subjective and intersubjective uses of generalizations in English conversations. In Robert Englebretson (ed.), Stancetaking in discourse, 111-37. Philadelphia: John Benjamins.

Schiffrin, Deborah (1987). Discourse markers. New York: Cambridge University Press.

Sidnell, Jack (2006). Coordinating gesture, talk, and gaze in reenactments. Research on Language and Social Interaction 39:377-409.

Silverstein, Michael (1979). Language structure and linguistic ideology. In Paul Clyne, William Hanks, \& Carol Hofbauer (eds.), The elements: A parasession on linguistic units and levels, 193-24. Chicago: Chicago Linguistic Society.

_ (1993) Metapragmatic discourse and metapragmatic function. In John Lucy (ed.), Reflexive language: Reported speech and metapragmatics, 33-58. Cambridge: Cambridge University Press.

(1997). The improvisational performance of culture in realtime discursive practice. In R. Keith Sawyer (ed.), Creativity in performance, 265-312. Greenwich, CT: Ablex.

Skarzynska, Krystyna (2002). We and they in Polish political discourse. In Anna Duszak (ed.), Us and others: Social identities across languages, discourses and cultures, 249-64. Philadelphia: John Benjamins.

Streeck, Jurgen (1993). Gesture as communication I: Its coordination with gaze and speech. Communication Monographs 60:275-99.

(1995). On projection. In Ester Goody (ed.), Social intelligence and interaction, 87-110. New York: Cambridge University Press.

(2008). Gesture in political communication: A case study of the Democratic presidential candidates during the 2004 primary campaign. Research in Language and Social Interaction 41(2):154-86. (2009). Gesturecraft: The manu-facture of meaning. Philadelphia: John Benjamins.

Stivers, Tanya, \& Jack Sidnell (2005). Introduction: Multimodal interaction. Semiotica 156:1-20.

Studdert, David (2005). Conceptualizing community: Beyond the state and individual. New York: Palgrave.

Widdicombe, Sue (1998). Identity as an analysts' and participants' resource. In Charles Antaki \& Sue Widdicombe (eds.), Identities in talk, 191-206. London: Sage.

Wodak, Ruth; Rudolf Cillia; Martin Reisigl; \& Karin Liebhart (1999). The discursive construction of national identity. London: Sage.

(Received 7 March 2011; revision received 11 September 2011; accepted 19 September 2011; final revision received 9 December 2011) 